\title{
RANCANG BANGUN ALAT PENDETEKSI TEGANGAN LISTRIK UNTUK TEKNISI INDIHOME DI PT. TELKOM AKSES WITEL MAKASSAR
}

\author{
Andi Muhammad Arif Bijaksana ${ }^{1}$, Ardyansah ${ }^{2}$, Faridah ${ }^{3}$, Masfuad Muttaqin $\mathrm{NH}^{4}$ \\ ${ }^{1,2,3,4}$ Program Studi Teknik Elektro Universitas Islam Makassar, Makassar, Sulawesi Selatan, Indonesia \\ Email: ${ }^{1}$ andimarifbijaksana.dty@uim-makassar.ac.id, ${ }^{2}$ Ardyansal8@gmail.com, \\ ${ }^{3}$ faridah.dty@uim-makassar.ac.id, ${ }^{4}$ masfuadmuttaqinnh@gmail.com
}

\begin{abstract}
The development of internet network infrastructure in Indonesia is inseparable from the presence of technicians to turn on or distribute internet services to the customer's home. Not infrequently the technicians experience work accidents due to electric shock. The number of work accidents due to electric shock pushed us to design a device that is able to detect electricity early or remotely and easy to use independent technicians so as to minimize work accidents due to electric shock. The objectives of this study are: 1) Designing a voltage detector located around the location of the indihome technician's work. 2) Implement an electric voltage detector on indihome technicians. By using a tool design method designed using applications such as Electronics Workbench (EWB), PCB Express (Printed Circuit Board), Sketchup. And also assembled using tools \& materials that are easily found in electronic stores. LED (Light Emitting Diode \& Buzzer serves as an indicator of the presence of electrical hazards around the technician's work location. The results of this study are: 1) This tool is able to detect electrical voltages from a minimum distance of $0 \mathrm{~mm}$ to $400 \mathrm{~mm}$. 2) This tool is shaped like a watch so that it is easy to use indihome technicians in working and does not interfere with the work process.
\end{abstract}

Keywords-Dangerous electricity, design, electric voltage detectors, Indihome Technicians.

Intisari-Pembangunan infrastruktur jaringan internet di Indonesia tidak terlepas dari keberadaan teknisi untuk mendistribusikan layanan internet sampai ke rumah pelanggan. Tidak jarang para teknisi mengalami kecelakaan kerja akibat tersengat listrik. Banyaknya kecelakaan kerja akibat tersengat listrik mendorong untuk merancang sebuah alat yang mampu mendeteksi listrik secara dini atau dari jarak jauh sehingga mampu meminimalisir kecelakaan kerja akibat tersengat listrik. Tujuan dari penelitian ini adalah merancang dan mengimplemntasikan alat pendeteksi tegangan listrik yang berada disekitar lokasi kerja teknisi indihome. Dengan menggunakan metode perancangan alat yang dirancang menggunakan aplikasi seperti Electronics Workbench (EWB), Express PCB (Printed Circuit Board), Sketchup. Dan juga dirakit menggunakan alat \& bahan yang mudah ditemukan di toko-toko elektronik. LED (Light Emitting Diode dan Buzzer berfungsi sebagai indikator akan adanya bahaya listrik yang ada disekitar lokasi kerja teknisi. Hasil penelitian ini adalah: 1) Alat ini mampu mendeteksi tegangan listrik dari jarak minimal 0 mm sampai dengan $400 \mathrm{~mm}$. 2) Alat ini berbentuk seperti jam tangan sehingga mudah digunakan teknisi indihome dalam bekerja dan tidak mengganggu proses kerja.

Kata kunci-Bahaya Listrik, Rancang Bangun, Pendeteksi Tegangan Listrik, Teknisi Indihome.

\section{PENDAHULUAN}

Dalam proses bisnis PT. Telkom Akses baik dari sisi pembangunan infrastruktur sampai proses instalasi jaringan internet indihome sampai ke rumah pelanggan, sering terjadi kecelakaan kerja akibat tersengat listrik. Hal tersebut terjadi karena infrastruktur jaringan PT. Telkom Akses bersinggungan dengan kabel-kabel listrik milik PLN (Perusahaan Listrik Negara). Tingginya angka kecelakaan kerja akibat tersengat listrik mendorong kami untuk merancang sebuah alat pendeteksi tegangan listrik yang akan digunakan untuk mendeteksi tegangan listrik tanpa menyentuh sumber tegangan atau kabel listrik yang berada disekitar lokasi kerja teknisi. Lokasi kerja yang dimaksud adalah lokasi pada saat melakukan instalasi penarikan kabel, menaiki tiang, sampai ke rumah pelanggan [1][2]. Berdasarkan latar belakang masalah tersebut, maka penelitian ini mengusulkan untuk merancang dan mengimplemntasikan alat yang dapat mendeteksi tegangan listrik berbahaya yang berada disekitar lokasi kerja teknisi indihome PT. Telkom Akses Witel Makassar. Diharapkan hasil penelitian ini dapat digunakan untuk mendeteksi tegangan listrik tanpa menyentuh sumber tegangan atau kabel listrik yang berada di sekitar lokasi kerja teknisi indihome, meminimalisir kecelakaan kerja akibat sengatan listrik yang dialami teknisi indihome, dan meningkatnya rasa aman dalam bekerja pada teknisi indihome.

\section{LANDASAN TEORI}

A. Sejarah Singkat PT. Telkom Akses

PT. Telkom Akses (PTTA) merupakan anak perusahaan PT Telekomunikasi Indonesia, Tbk (Telkom) yang sahamnya dimiliki sepenuhnya oleh Telkom. PTTA bergerak dalam bisnis penyediaan layanan konstruksi dan pengelolaan infrastruktur jaringan [3].

Tabel I.

Profile PT. Telkom Akses (Sumber:Apps company policy portal PT. Telkom Akses)

\begin{tabular}{|c|c|}
\hline NAMA PERUSAHAAN & PT. Telkom Akses \\
\hline \multirow{2}{*}{ ISO } & 05-Apr-13 \\
\cline { 2 - 2 } & $\begin{array}{c}\text { *ISO 9001:2008 Quality } \\
\text { Management System }\end{array}$ \\
\hline
\end{tabular}




\begin{tabular}{|c|c|}
\hline $\begin{array}{c}\text { TECHNOLOGY } \\
\text { OWNER LICENSE } \\
\text { (SUPPORT) }\end{array}$ & $\begin{array}{c}\text { Alcatel Lucent, } \\
\text { FIBERHOME, HUAWEI, } \\
\text { ZTE }\end{array}$ \\
\hline TANGGAL DIDIRIKAN & 12 Desember 2012 \\
\hline & Jl. S. Parman Kav. 8 Jakarta \\
Barat 11440 \\
PLAMAT LENGKAP & Telp. / Fax : +62-21-2933- \\
PERUSAHAAN & 7000 / +62-21-2933-6000 \\
& http://www.telkomakses.co.id \\
\hline
\end{tabular}

B. Hukum Biot Savart

Tahun 1819 Hans Christian Oersted menemukan bahwa jarum kompas dibelokkan oleh suatu kawat berarus.Kemudian tahun 1920an Jean-Baptiste Biot dan Felix Savart melakukan eksperimen untuk menentukan gaya yang bekerja pada kompas oleh suatu kawat berarus.

Sebuah kawat apabila dialiri oleh arus listrik akan menghasilkan medan magnet yang garis-garis gayanya berupa lingkaran-lingkaran yang berada di sekitar kawat tersebut. Arah dari garis-garis gaya magnet ditentukan dengan kaidah tangan kanan (apabila kita menggenggam tangan kanan ibu jari sebagai arah arus listrik sedang keempat jari yang lain merupakan arah medan magnet). (Hk. Oersteid). [4][5]

Adapun hasil percobaan Biot \& Savart adalah:

- $\mathrm{dB}$ adalah medan magnetik yang diproduksi oleh potongan kecil kawat

- ds adalah vektor panjang dari potongan kecil kawat yang searah dengan arah arus

- $\quad r$ adalah vektor posisi dari potongan kawat ke titik dimana medan magnetik ingin diukur

- I adalah arus dalam kawat

- $\quad \theta$ adalah sudut antara ds \& r

Semua hasil di atas dapat disimpulkan dalam suatu

"hukum" yang dikenal sebagai Hukum Biot-Savart

- $\quad \mathrm{dB}$ tegak lurus ds

- $\mathrm{dB}$ tegak lurus $\mathrm{r}$

- $\mathrm{dB}$ berbanding terbalik $\mathrm{r} 2$

- $\quad \mathrm{dB}$ sebanding dengan arus I

- $\mathrm{dB}$ sebanding dengan ds

- $\mathrm{dB}$ sebanding dengan $\sin \theta$

Masukkan Konstanta:

$$
d B=\propto I \frac{d s \times r}{|r|^{2}}
$$

$$
d B=\left[\frac{\mu 0}{4 \pi}\right] I \frac{d s \times r}{|r|^{2}}
$$

Dimana $\mu 0$ adalah permeabilitas ruang hampa

$$
u 0=4 \pi \times 10^{-7} \frac{T m}{A}
$$

C. Komponen-komponen Elektronik

Rangkaian pendeteksi ini adalah rangkaian yang digunakan untuk mendeteksi frekuensi dari listrik AC. Rangkaian ini menggunakan IC 4017 yang mana pin 14 dari IC dihubungkan dengan probe sebagai antena untuk mendeteksi frekuensi tersebut [6][7].

Daftar Komponen:
1. IC 4017
2. Transistor BC547
1 buah
1 buah
3. Elco $100 \mathrm{uF}$
1 buah
4. Resistor $1 \mathrm{k}$
1 buah
5. Resistor $100 \mathrm{ohm} \quad 1$ buah
6. LED 1 buah
7. Buzzer 1 buah
8. Baterai $9 \mathrm{~V} \quad 1$ buah

\section{METODE PENELITIAN}

A. Batasan Penelitian

Kota Makassar termasuk daerah yang beriklim tropis, karena letaknya menghampiri garis khatulistiwa. Berdasarkan pencatatan Stasiun Meteorologi Maritim Paotere, karakteristik iklim Kota Makassar pada tahun 2009 sebagai berikut [8]:

1. Kelembaban udara berkisar antara $67 \%$ (bulan Agustus) - 90\% (bulan Januari) dengan lama penyinaran matahari rata-rata 70 persen.

2. Curah hujan tahunan rata-rata $2560.8 \mathrm{~mm}$, dimana curah hujan tertinggi dicapai pada bulan Januari dengan rata-rata $922.8 \mathrm{~mm} / \mathrm{bulan}$ dan terendah pada bulan Oktober berkisar $15.7 \mathrm{~mm} / \mathrm{bulan}$ dengan jumlah hari hujan sekitar 128 hari hujan per tahun.

3. Temperatur udara rata-rata di Kota Makassar berkisar antara $26.2-29.3^{\circ} \mathrm{C}$.

4. Kecepatan angin rata-rata $5.2 \mathrm{Knot} / \mathrm{Jam}$

Agar penyelesaian masalah yang dilakukan tidak meyimpang dari ruang lingkup yang ditentukan dan sesuai dengan karakteristik Kota Makassar, maka akan dilakukan pembatasan masalah. Adapun batasan masalah ini ialah sebagai berikut:

1. Aliran listrik yang akan dideteksi adalah aliran listrik yang memiliki minimal frekuensi $50 \mathrm{~Hz}$ atau 220 VAC.

2. Lokasi penelitian adalah wilayah kerja PT. Telkom Akses Witel Makassar khususnya dalam kota Makassar.

3. Teknisi Indihome yang melaksanakan kegiatan instalasi penarikan kabel, menaiki tiang, sampai ke rumah pelanggan.

4. Kondisi cuaca sangat mempengaruhi alat ini karena casing yang digunakan oleh alat ini belum tahan terhadap air, oleh karena itu alat ini tidak bisa digunakan saat cuaca hujan atau dalam kondisi basah.

B. Waktu dan Tempat Penelitian

Penelitian ini berlangsung selama kurang lebih 2 (dua) bulan terhitung mulai bulan Januari hingga maret minggu pertama. Penelitian ini kami laksanakan di:

1. Laboratorium Fakultas Teknik Universitas Islam Makassar.

2. Fiber Academy PT. Telkom Akses Witel Makassar.

C. Alat dan Bahan

Alat dan Bahan yang digunakan dalam penelitian kali sangat mudah ditemukan di toko-toko eletronik. Tabel II merupakan daftar alat dan bahan yang digunakan. 
Tabel II.

Profile PT. Telkom Akses (Sumber:Apps company policy portal PT. Telkom Akses)

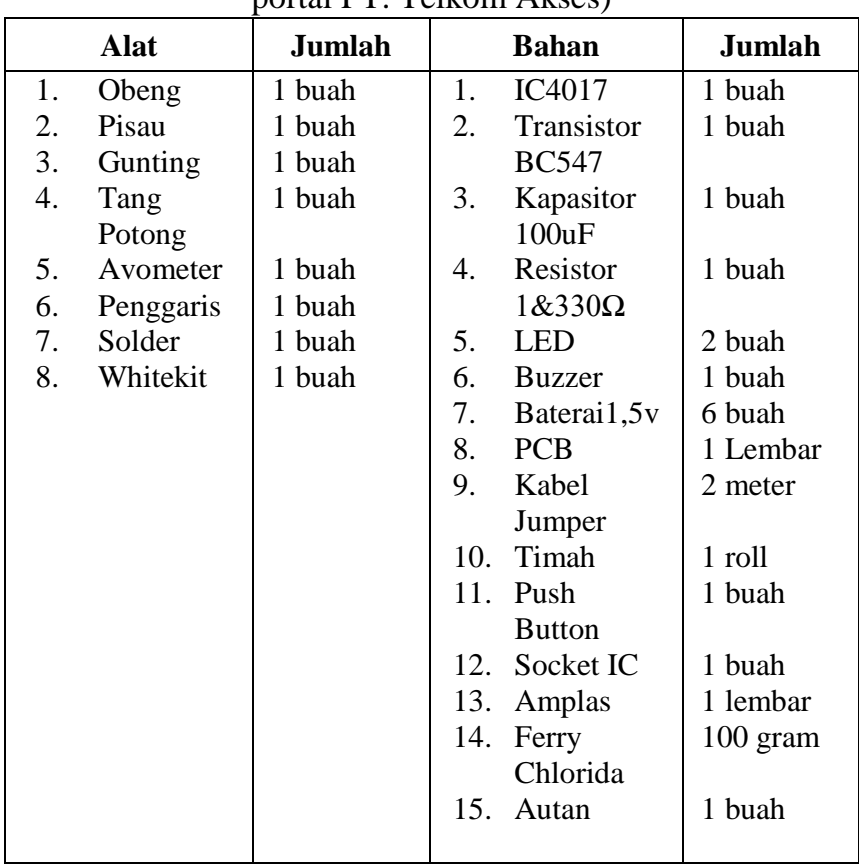

Adapun hardware dan software yang digunakan dalam penelitian ini, antara lain :

1. Komputer PC / Laptop

2. Sistem Operasi Microsoft Windows 10

3. Microsoft Office World, Excel, Power Point 2016

4. EWB (Electronic Workbench)

5. PCB Express

6. Sketchup 2017

7. Printer Canon MP237

8. Youtube

D. Desain Perancangan

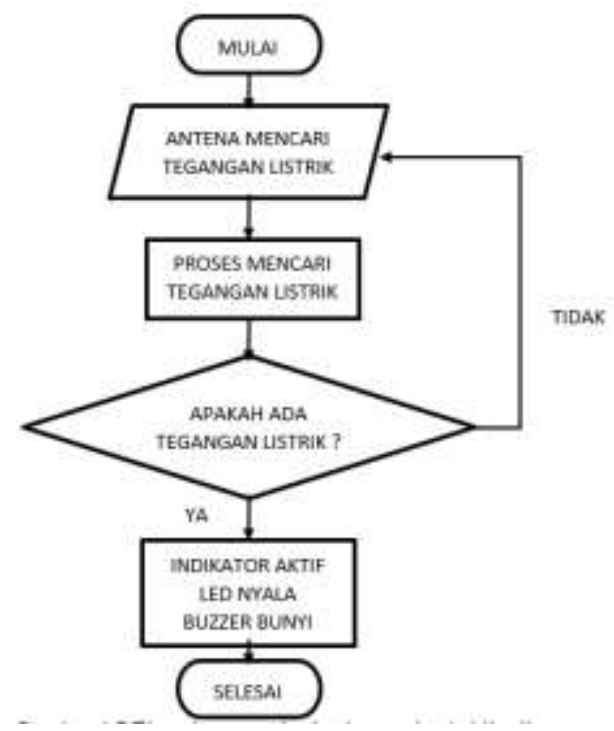

Gambar 1. Flowchart cara kerja alat pendeteksi listrik

Pada penelitian ini rangkaian pendeteksi listrik akan dikemas dalam bentuk gelang agar lebih mudah digunakan teknisi indihome dalam proses kerja baik didalam ruangan ataupun diluar ruangan. Untuk memperluas jangkaian deteksi atau kepekaan dari rangkaian tersebut maka akan ditambahkan antena sehingga pada jarak $+-30 \mathrm{~cm}$ dari tegangan listrik, maka rangkaian akan bekerja dengan memberi peringatan pada teknisi melalui indikator LED merah menyala dan juga BUZZER akan berbunyi. Flowchart bekerjanya alat dapat dilihat pada Gambar 1.

Perancangan pada penelitian ini menggunakan aplikasi EWB (Electronic Workbench) dan juga Express PCB. Desain perancangan dapat dilihat pada Gambar 2 dan 3.

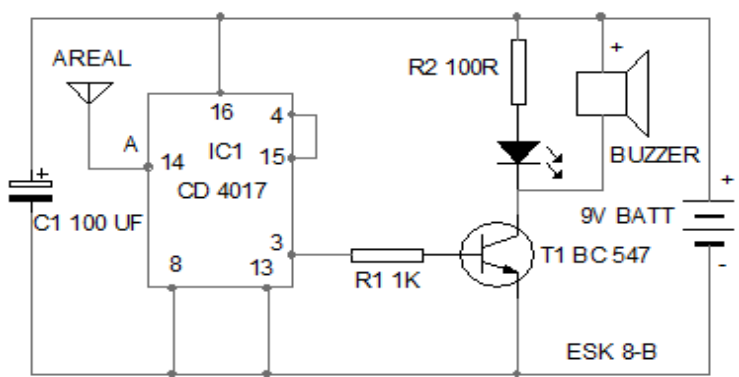

Gambar 2. Skematik rangkaian (Sumber: electronic workbench)

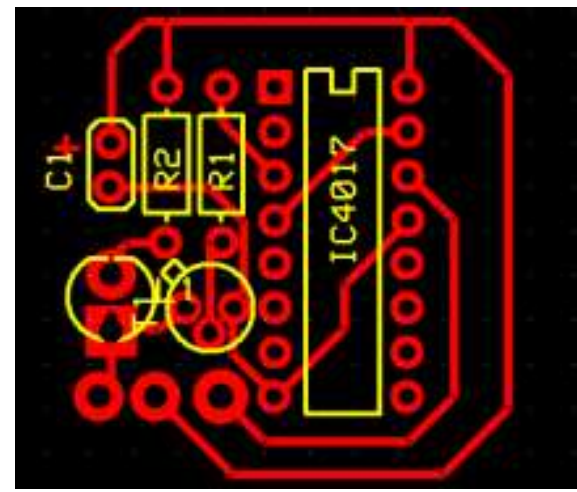

Gambar 3. Desain layout PCB (Printed Circuit Board)

Saat pin 14 IC 4017 menangkap sinyal frekuensi dari listrik AC, maka output pertama pin 3 mengaktifkan transistor BC547 sehingga LED dan Buzzer aktif dengan logika 0 dan 1 secara terus menerus. Hal ini dikarenakan lisrik AC menghasilkan gelombang sinus bolak-balik dan tidak stabil. Blok diagram rangkaian ini dapat dilihat pada Gambar 4.

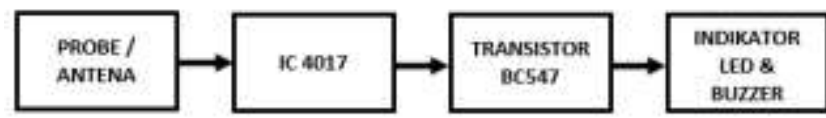

Gambar 4. Blok diagram alat pendeteksi listrik

E. Langkah-langkah Perakitan Alat

Proses perakitan alat ini memiliki beberapa tahapan yaitu:

1. Desain layout PCB pada aplikasi Express PCB.

2. Print hasil desain layout PCB pada kertas HVS ukuran A4.

3. Potong papan PCB dengan ukuran $4 \times 3 \mathrm{~cm}$.

4. Tempelkan hasil print layout PCB ke papan PCB yang telah dipotong. 
5. Oleskan autan pada permukaan kertas sampai merata keseluruh bagian papan PCB.

6. Lapisi permukaan kertas dengan menggunakan plastic mika tipis kemudian gosok menggunakan uang koin.

7. Setelah jalur PCB menempel, bersihkan sisa kertas.

8. Pastikan kondisi jalur PCB tidak ada yang terputus kemudian larutkan papan PCB menggunakan air panas yang telah dicampurkan dengan ferry clorida untuk melarutkan tembaga yang ada pada papan PCB sekitar 30 menit dengan terus menggoyangkan wadahnya.

9. Bersihkan sisa-sisa tinta yang menempel pada jalur PCB yang telah dilarutkan menggunakan amplas halus.

10. Keringkan papan PCB kemudian lakukan pengecekan jalur PCB untuk memastikan tidak ada sambungan yang terputus atau saling bersinggungan.

11. Lubangi titik-titik kaki komponen pada papan PCB menggunakan mata bor $0.8 \mathrm{~cm}$.

12. Pastikan semua komponen yang akan disolder dalam kondisi baik dengan menggunakan Avometer.

13. Pasang dan solder komponen-komponen yang akan digunakan.

Selanjutnya untuk proses cetak casing alat ini menggunakan printer 3D dari jasa percetakan 3D Print Sulawesi. Berikut tahap-tahap mencetak casing alat ini:

1. Desain casing dalam bentuk 3 dimensi menggunakan aplikasi sketchup versi 2017.

2. Print hasil desain casing menggunakan printer $3 \mathrm{D}$.

3. Bersikan hasil print dengan menggunakan amplas halus.

4. Pasangkan tali jam pada posisi yang telah di sediakan.

F. Metode Pengumpulan Data

Data penelitian yang diperlukan dalam penyusunan laporan tugas akhir diperoleh melalui:

\section{Studi Literatur}

Tahap ini merupakan tahap pengumpulan informasi yang diperlukan untuk pembuatan alat. Informasi tersebut di peroleh dengan cara membaca literatur ataupun bukubuku yang berhubungan.

\section{Perencanaan dan implementasi}

Pada tahap ini akan dilakukan perencanaan dan implementasi terhadap alat berdasarkan hasil studi literatur dan pada tahap ini pula akan dilakukan proses dilakukan pembuatan alat sesuai dengan data-data yang telah ditentukan.

3. Uji coba alat dan pengukuran

Pada tahap ini akan dilakukan uji coba alat dan pengukuran terhadap perakitan alat serta dilakukan pengukuran.

\section{Wawancara}

Teknik pengumpulan data yang dilakukan melalui tatap muka dan tanya jawab langsung antara peneliti dan narasumber/teknisi indihome. Seiring perkembangan teknologi, metode wawancara dapat pula dilakukan melalui media-media tertentu, misalnya telepon, email, Gform, atau social media (whatsapp, telegram, Instagram, facebook).

\section{HASIL DAN PEMBAHASAN}

Berikut hasil perancangan dan bentuk dari alat pendeteksi tegangan listrik ini yang kami beri nama D'Volt (Detector Voltage):

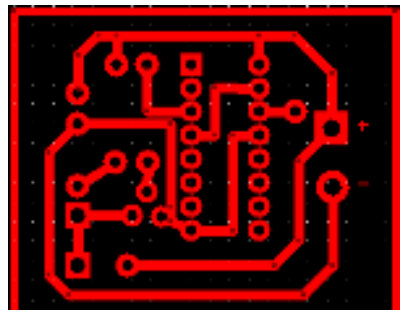

Gambar 5. Layout PCB (Printed Circuit Board)

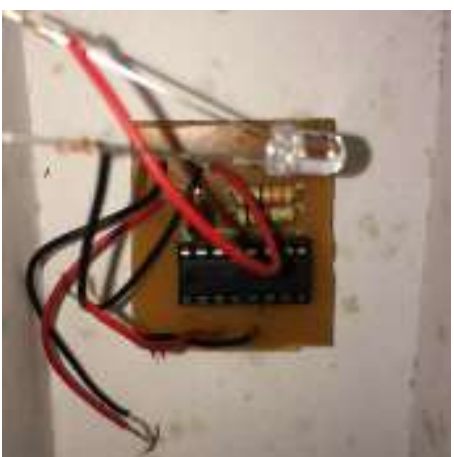

Gambar 6. Bentuk rangkaian pendeteksi tegangan listrik

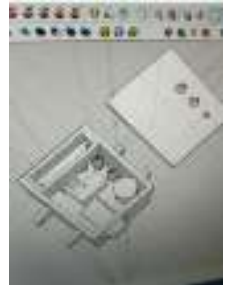

Gambar 7. Desain casing

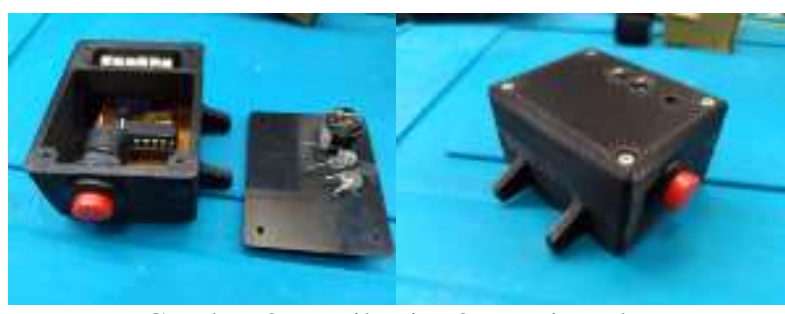

Gambar 8. Hasil print 3D casing alat

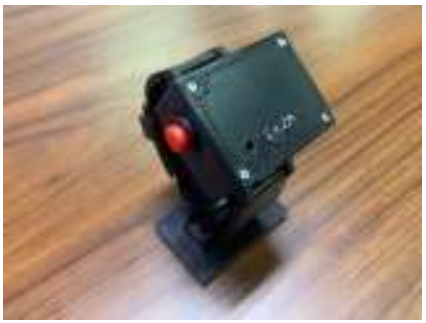

Gambar 9. Tampilan keseluruhan alat

Dimensi dari casing alat ini adalah 4,5 x 3,5 x 2,5 cm dan berat totalnya 89,670 gram. Hasil print casing alat ini menjadi 2 bagian yaitu:

1. Bagian box untuk tempat menyimpan rangkaian,

baterai, dan push button/saklar. 
2. Penutup box untuk tempat menempel LED dan BUZZER.

Sebelum dilakukan uji coba alat ini kepada para teknisi, maka terlebih dahulu melakukan beberapa pengujian sistem dalam skala lab, meliputi:

A. Hasil Pengujian Jarak

Pengujian jarak ini bertujuan untuk mengetahui seberapa jauh jangkauan deteksi alat ini terhadap tegangan yang berada disekitarnya, Dengan menggunakan eterna cable $3 \times 1.5 \mathrm{~mm}$ dan dialiri tegangan $220 \mathrm{~V}$ maka kami memperoleh hasil pengujian sebagai berikut:

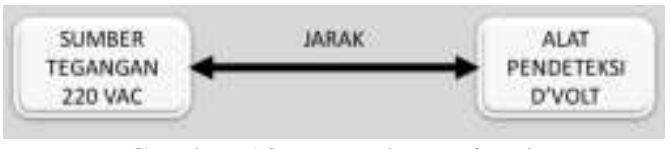

Gambar 10. Pengukuran jarak

Tabel III.

Hasil pengukuran jarak deteksi terhadap LED

\begin{tabular}{|c|c|c|}
\hline NO & JARAK & STATUS LED \\
\hline 1 & $0 \mathrm{~mm}$ & ON \\
\hline 2 & $50 \mathrm{~mm}$ & ON \\
\hline 3 & $100 \mathrm{~mm}$ & ON \\
\hline 4 & $150 \mathrm{~mm}$ & ON \\
\hline 5 & $200 \mathrm{~mm}$ & ON \\
\hline 6 & $250 \mathrm{~mm}$ & ON \\
\hline 7 & $300 \mathrm{~mm}$ & ON \\
\hline 8 & $350 \mathrm{~mm}$ & ON \\
\hline 9 & $400 \mathrm{~mm}$ & ON \\
\hline 10 & $450 \mathrm{~mm}$ & OFF \\
\hline
\end{tabular}

Dari hasil pengukuran yang telah dilakukan, jarak pengukuran terjauh yang mash dapat dilakukan adalah $400 \mathrm{~mm}$ dan lampu LED masih menyala dengan pancaran sinar yang konstan atau tidak redup. Hal ini menunjukkan juga bahwa jarak alat dengan sumber tegangan listrik tidak mempengaruhi terang atau redupnya LED ketika aktif. Pada batasan masalah yang dideteksi adalah tegangan listrik minimal $220 \mathrm{VAC}$ atau Frekuensi $50 \mathrm{~Hz}$ tanpa menyentuh sumber tegangannya, sedangkan pada hasil pengukuran ini alat mampu mendeteksi maksimal $400 \mathrm{~mm}$, maka analisis fungsi alat sudah sesuai. Setelah lebih dari $400 \mathrm{~mm}$ alat pendeteksi sudah tidak mendeteksi sinyal frekuensi tegangan listrik, sehingga LED sudah tidak dapat menyala.

Tabel IV.

Hasil pengukuran jarak deteksi terhadap buzzer

\begin{tabular}{|c|c|c|}
\hline NO & JARAK & STATUS BUZZER \\
\hline 1 & $0 \mathrm{~mm}$ & ON \\
\hline 2 & $50 \mathrm{~mm}$ & ON \\
\hline 3 & $100 \mathrm{~mm}$ & ON \\
\hline 4 & $150 \mathrm{~mm}$ & ON \\
\hline
\end{tabular}

\begin{tabular}{|c|c|c|}
\hline NO & JARAK & STATUS BUZZER \\
\hline 5 & $200 \mathrm{~mm}$ & ON \\
\hline 6 & $250 \mathrm{~mm}$ & ON \\
\hline 7 & $300 \mathrm{~mm}$ & ON \\
\hline 8 & $350 \mathrm{~mm}$ & ON \\
\hline 9 & $400 \mathrm{~mm}$ & ON \\
\hline 10 & $450 \mathrm{~mm}$ & OFF \\
\hline
\end{tabular}

Sama halnya dengan hasil pengukuran LED, jarak pengukuran terjauh yang masih dapat dilakukan adalah $400 \mathrm{~mm}$ dan BUZZER masih berbunyi dengan suara yang konstan/tetap atau tidak mengecil suaranya. Hal ini menunjukkan juga bahwa jarak alat dengan sumber tegangan listrik tidak mempengaruhi nyaring atau tidaknya bunyi dari BUZZER ketika aktif. Pada batasan masalah yang dideteksi adalah tegangan listrik minimal 220 VAC atau Frekuensi $50 \mathrm{~Hz}$ tanpa menyentuh sumber tegangannya, sedangkan pada hasil pengukuran ini alat mampu mendeteksi maksimal $400 \mathrm{~mm}$, maka analisis fungsi alat sudah sesuai. Setelah lebih dari $400 \mathrm{~mm}$ alat pendeteksi sudah tidak mendeteksi sinyal frekuensi tegangan listrik, sehingga BUZZER sudah tidak dapat berbunyi lagi.

B. Rumus Perhitungan Jarak Induksi Kabel

Untuk mengetahui jarak jangkauan alat yang diusulkan dalam penelitian ini, dapat digunakan hukum biot savart untuk menghitung jarak induksi dari kabel yang terdeteksi, berikut penjelasannya [2]:

$\mathrm{B}=\mu 0 i / 2 \pi a$

Keterangan:

$\mathrm{B}=$ induksi magnetic (tesla)

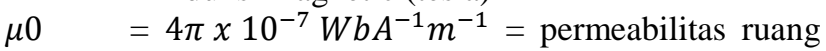
hampa

$\mathrm{i}=$ kuat arus listrik (A)

a $\quad=$ jarak titik dari kawat $(\mathrm{m})$

Berikut hasil perhitungannya:

i $\quad=2 \mathrm{~A}$

Besar medan magnet pada jarak $\mathrm{a}=5 \mathrm{~cm}=5 \times 10^{-2}$ adalah :

$\mathrm{B}=\mu 0 i / 2 \pi a$

$\mathrm{B}=4 \pi \times 10^{-7} W b A^{-1} \mathrm{~m}^{-1} \times 2 A /\left(2 \pi \times 5 \times 10^{-2} \mathrm{~m}\right)$

$\mathrm{B}=8 \times 10^{-6} T$

Besar medan magnet pada jarak $\mathrm{a}=10 \mathrm{~cm}$ dari kawat adalah:

$\mathrm{B}=\mu 0 i / 2 \pi a$

$\mathrm{B}=\mu 0 i /\left[2 \pi a\left(\frac{10 \mathrm{~cm}}{5 \mathrm{~cm}}\right)\right]$

$\mathrm{B}=8 \times 10^{-6} T / 2$

$\mathrm{B}=4 \times 10^{-6} T$

C. Hasil Uji Lapangan Penggunaan Alat

Pengujian ini dilakukan oleh 7 orang teknisi yang tersebar di 7 lokasi kerja PT. Telkom Akses Makassar, yaitu pada STO SUDIANG, STO KIMA, STO TAMALANREA, STO ANTANG, STO PANAKKUKANG, STO BALAIKOTA, dan STO MATTOANGING. 
Untuk mendapatkan data hasil pengujian teknisi terhadap alat ini kami menggunakan kuesioner penelitian dengan menggunakan GForm, berikut hasilnya:

1. Kinerja Alat

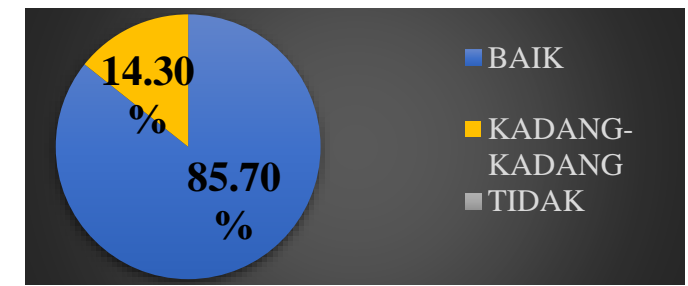

Gambar 11. Diagram kinerja alat pendeteksi listrik

Alat pendeteksi listrik ini berfungsi secara baik ketika digunakan dalam bekerja dengan skor kepuasan $85,70 \%$. Adapun 14,30\% respon yang menyatakan kadang-kadang diakibatkan posisi alat ketika digunakan telah mencapai ambang batas jarak terhadap sumber listrik.

2. Perasaan Teknisi Setelah Menggunakan Alat Pendeteksi

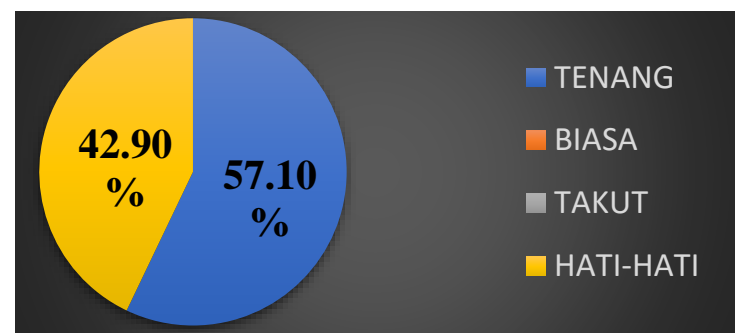

Gambar 12. Diagram perasaan teknisi setelah menggunakan alat pendeteksi

Data tersebut menunjukkan para teknisi merasa lebih tenang dalam bekerja sebanyak $57,10 \%$ karena tidak merasa takut lagi akan adanya listrik berbahaya di sekitar lokasi kerjanya. Disamping itu para teknisi juga jauh lebih berhati-hati dalam bekerja ketika alat ini telah mendeteksi adanya bahaya listrik di sekitarnya, dengan begitu kecelakaan kerja akibat sengatan listrik dapat diminimalisir.

\section{Tingkat Kegunaan Alat Pendeteksi Listrik Bagi} Teknisi

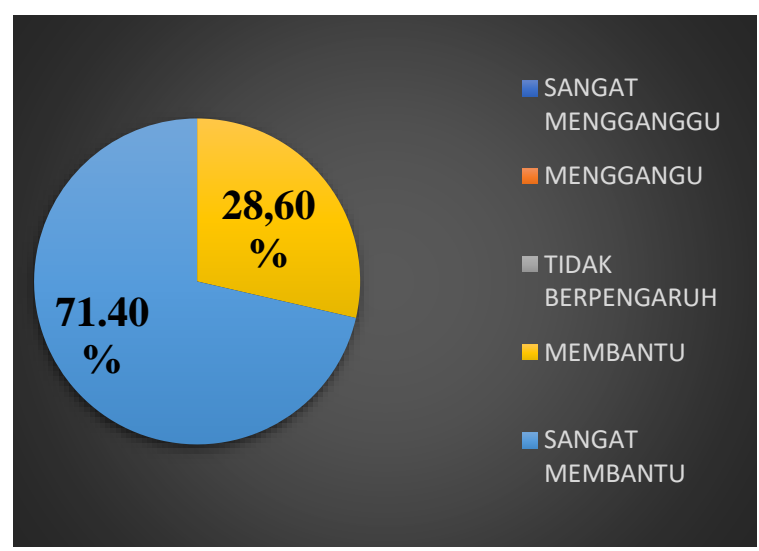

Gambar 13. Diagram tingkat kegunaan alat pendeteksi listrik
Dari data tersebut dapat kami simpulkan bahwa dari 7 teknisi yang telah menggunakan alat ini semuanya merasa terbantu dan yang merasa sangat terbantu mencapai angka $71,40 \%$.

\section{Rating Kinerja Alat Pendeteksi Listrik}

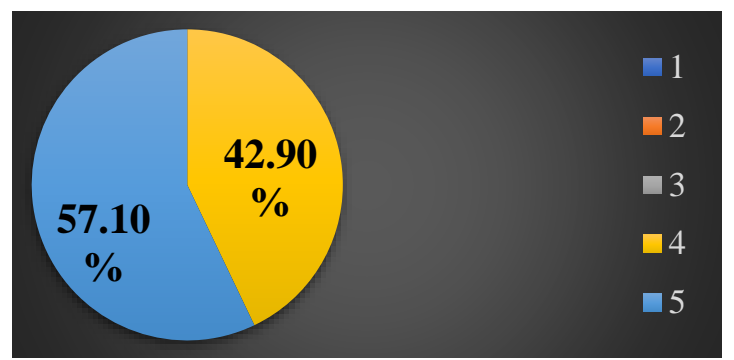

Gambar 14. Diagram rating kinerja alat pendeteksi listrik

Dalam skala 1-5 dimana 1 nilai terendah dan 5 penilaian tertinggi para teknisi memberi penilaian 5 sebanyak $57,10 \%$ dan nilai 4 sebanyak $42,90 \%$. Hal ini menunjukkan alat ini mendapat respon positif dari para teknisi karena dapat membantu dan menjaga para teknisi dari bahaya listrik juga terhindar dari kecelakaan kerja akibat tersengat listrik.

\section{KESIMPULAN DAN SARAN}

Setelah melakukan perancangan dan uji coba terhadap alat yang telah dibuat, maka dapat disimpulkan bahwa alat yang berbentuk seperti jam tangan ini mudah digunakan dan memiliki fitur yang canggih, karena telah dilengkapi indikator LED (Light Emiting Diode) dan Buzzer sebagai pengingat akan adanya bahaya listrik di lokasi kerja teknisi indihome. Ini terbukti respon yang positif diberikan oleh para teknisi setelah menggunakan alat ini, serta alat ini mampu mendeteksi tegangan minimal 220 VAC tanpa menyentuh sumber tegangannya dari jarak minimal $0 \mathrm{~mm}$ sampai dengan $400 \mathrm{~mm}$.

Untuk penelitian selanjutnya, agar alat ini diperkecil casing dan membuat alat ini tahan terhadap air, baterai menggunakan baterai isi ulang yang dilengkapi indikator daya, dan juga menambah jarak jangkauan agar lebih sempurna ketika digunakan. Selain itu, untuk fakultas Teknik penelitian ini sebaiknya dilanjutkan untuk keselamatan teknisi indihome dan untuk masyarakat umum diharapkan sumbangan pemikirannya dari berbagai disiplin ilmu untuk menyempurnakan penelitian ini. Agar dapat digunakan bukan hanya teknisi indihome tetapi juga sebagai alat bantu peralatan listrik rumah tangga. 


\section{REFERENSI}

[1] Herwiyanto. 2013. Pengawasan K3 Listrik.

Di

https://tiarasalsabilatoniputri.files.wordpres s.com (di akses 1 September 2018).

[2] Sayogo, Bartien. 2014. Penjelasan PUIL 2011 Edisi 2014. Jakarta. Copper Alliance.

[3] Portal Telkom Akses. 2018. Company Profile. Di https://apps.telkomakses.co.id (di akses 29 Agustus 2018).

[4] Ardra. 2015. Induksi Medan Magnet \& Hukum Biot Savart. di https://ardra.biz/induksi-medan-magnet/(di akses 3 Maret 2019).

[5] Blocher, Richard. 2004. Dasar Elektronika Ed.II. Yogyakarta. Andi.

[6] Pramudya. 2017. Pengertian dan Fungsi Pin IC4017. Di

http://www.bukaelektro.com (di akses 30 Agustus 2018).

[7] Listiyarini, Ratih. 2018. Dasar Listrik dan Elektronika. Yogyakarta. Deepublish.

[8] Badan Pusat Statistika Kota Makassar, 2010. Makassar Dalam Angka 2010 (Makassar in Figure 2010). Makassar. UD Areso. 